\title{
Task Influences on Students' Collaboration in Mathematics Teaching
}

\author{
Joakim Samuelsson \\ Linköping University, Sweden \\ joakim.samuelsson@liu.se
}

\author{
Karin Forslund Frykedal \\ Linköping University, Sweden \\ Karin.Forslund.frukedal@liu.se
}

\begin{abstract}
The aim of this article was to investigate students' experience of a given mathematical problem and the types of group interaction and communication that occur when students experience a task as (a) too difficult, (b) reasonable difficult or (c) too simple. Collaborative work with mathematical problems is a commonly used teaching method but one of the difficulties for teachers is to observe the learning processes of children who are working collaboratively. Earlier research has demonstrated that the task has an influence on the group processes and the group members' interaction. In this study we were interested in how tasks with different degree of difficulty influenced the students' when they work in a group with mathematical problem solving tasks. Four group work sessions were documented with a video camera and we found that students' different ways of experience a mathematical task affect the interactions processes, quality talk and certain social modes of thinking. The results show that teachers' settings of the problem and how the students manage the interaction processes in the group were important to what competencies students were exposed to and what they thereby were able to learn.
\end{abstract}

Keywords: Communication; Group interaction; Group work; Mathematical competencies; Task.

\section{Introduction}

In this study we investigated students interaction and communication in group work situations when they work with mathematical tasks they experience as (a) too difficult, (b) reasonable difficult or (c) too simple. Group work is a teaching strategy that promotes academic achievement and socializations (Baines, Blatchford \& Chowne, 2007; Gillies, 2003, Johnson \& Johnson, 2004; Oliveira \& Sadler, 2008; Summers, Beretvas, Svinicki \& Gorin, 2005). By interacting with others, students learn to inquire, share ideas, clarify differences, and construct new understandings. During a group work students could both be working in a group (i.e. cooperation) and working as a group (i.e. collaboration) with a group task. Working in a group may be a description of situations where students sit together in a group but working individually on separate parts of a group task. Consequently the work could go on without any or minimal interaction between the students. Working as a group, are often referred to as "real group work", where all group members are involved in and working on a common task in order to produce a joint outcome. Working as a group is characterised by a common effort, utilisation of the group's competences, including problem-solving and reflection (Hammar Chiriac, 2011a, 2011b; Ryve, Nilsson \& Pettersson, 2013; Webb \& Favier, 1999; Webb \& Mastergeorge, 2003).

Group work, from a learning perspective, could functions both as an object, that is learning to collaborate in groups, and as a means, that is as a base for obtaining knowledge (Baines et al., 2007; 
Gillies, 2003; Johnson \& Johnson 2004; Summers et al. 2005). In a recently completed study, teachers clearly demonstrated that they primarily expect the students to develop the ability to collaborate, and thereby use group work as an object, and not principally to acquire subject knowledge, during group work (Hammar Chiriac \& Forslund Frykedal, 2011).

An advantage of peer collaboration in a group work is in the scaffolding process whereby children help each other to progress. Giving and receiving help and explanations may widen their thinking skills, and verbalising can help children structure their thoughts (Leiken \& Zaslavsky, 1997). They thereby learn to use language to explain issues, which in turn helps them construct new ways of thinking (Webb \& Mastergeorge, 2003). This exchange may encourage children to engage in higher-order thinking (Becker \& Selter, 1996). Programmes that have attempted peer collaboration as a teaching method report good results, such as improved conceptual understanding and higher scores on problem-solving tasks (Goods \& Gailbraith, 1996; Leikin \& Zaslavsky, 1997). Research also shows that children working collaboratively achieve a combined higher performance output than children working individually (Samaha \& De Lisi, 2000). Several researchers (e.g. Rogoff, 1990; Samaha \& De Lisi, 2000; Webb \& Favier, 1999) argue that a key element of effective peer collaboration is the active exchange of ideas through verbal communication. However peer collaboration is not always associated with cognitive development (Doise \& Mugny, 1984; Tudge \& Winterhoff, 1993). It is suggested that the peer collaborations' impact depend on a set of factors such as age (Hogan \& Tudge, 1999), comparative ability level of partners (Garton \& Pratt, 2001), motivation (Gabriele \& Montecinos, 2001), confidence (Tudge, Winterhoff \& Hogan 1996), gender (Strough, Berg \& Meegan, 2001), and the task (Phelps \& Damon, 1989).

\section{The influence of the task}

One aspect which could help to affect group processes is the design of the task, since the type of task appears to determine group members' interaction (Gillies \& Boyle, 2010; Rojas-Drummond \& Mercer, 2003). Working on tasks that are open and discovery-based create more collaboration than working with close tasks (Cohen, 1994a, b; Hofer \& Pintrich, 1997) since it requires more discuss planning, decision making and division of labours as well as substantive content. Hertz-Lazarowitz (1989) also emphasized the importance of ensuring the learning tasks to be challenging. To establish task interdependence between the group members (Cohen, 1994a, b; Johnson \& Johnson, 2004) is another factor of importance to embed collaboration between the group members. Cohen (1994a, b) furthermore emphasise designing activities to ensure individual accountability on the part of all group members. The way a task is transferred and communicated, and the way it is perceived in the group affects the subsequent group processes (White \& Dinos, 2010). Järvenoja \& Järvele (2009) have emphasised that task structures affect the challenges students encounter but how the challenges are linked to the task structures and intrinsic group dynamics require further investigation.

\section{Mathematical competencies and communication}

Collaborative work with mathematical problems is a commonly used teaching method in several classrooms in Sweden. One of the difficulties for teachers is to observe the learning process of children who are working collaboratively. What do they discuss and how are they reasoning? Ross (1998) refers to the NCTM Commission on the Future of Standards questions concerning proof and mathematical reasoning: "One of the most important goals of mathematics courses is to teach children logical reasoning. This is a fundamental skill, not just a mathematical one. [...] While science verifies through observation, mathematics verifies through logical reasoning. [...] If reasoning ability is not developed in the children, then mathematics simply becomes a matter of following a set of procedures and mimicking examples without thought as to why they make sense (pp.112)." Thus, reasoning seems to be a fundamental component of mathematics.

The mathematics curriculum in compulsory school in Sweden has many components, but there is a strong emphasis on concepts of numbers and operations with numbers (National agency of education, 2011). Mathematics knowledge is defined as something more complex than concept of numbers and operations with numbers. Kilpatrick, Swafford and Findell (2001) argue for five strands which together build children's mathematical proficiency. In their report they discuss: 
1. Conceptual understanding is about comprehension of mathematical concepts, operations, and relationships. Students with conceptual understanding know more than isolated facts and methods. Items measuring conceptual understanding are for instance: "Your number is 123.45. Change the hundreds and the tenths. What is your new number?"

2. Procedural fluency refers to skills in carrying out procedures flexibly, accurately, efficiently, and appropriately. Students need to be efficient in performing basic computations with whole numbers (e.g., 6+7, 17-9, 8×4) without always having to refer to tables or other aids.

3. Strategic competence is the ability to formulate, represent, and solve mathematical problems. Kilpatrick et al. (2001, pp. 126) give the following example of item testing strategic competence: "A cycle shop has a total of 36 bicycles and tricycles in stock. Collectively there are 80 wheels. How many bikes and how many tricycles are there?"

4. Adaptive reasoning refers to the capacity for logical thought, reflection, explanation, and justification. Kilpatrick et al. (2001) gives the following example where students can use their adaptive reasoning. "Through a carefully constructed sequence of activities about adding and removing marbles from a bag containing many marbles, second graders can reason that $5+(-6)$ $=-1$. In the context of cutting short bows from a 12-meter package of ribbon and using physical models to calculate that 12 divided by $1 / 3$ is 36 , fifth graders can reason that 12 divided by $2 / 3$ cannot be 72 because that would mean getting more bows from a package when the individual bow is larger, which does not make sense" (p.130).

5. "Productive disposition is the habitual inclination to see mathematics as sensible, useful, and worthwhile, coupled with a belief in diligence and one's own efficacy" (Kilpatrick et al., 2001, p.5). Items measuring productive disposition are for instance: "How confident are you in the following situations? When you count $8-1=\ldots+3$ (completely confident, confident, fairly confident, not at all confident)."

Collaborative work with mathematical tasks is an educational activity that enhances learning through active participation. Students have the opportunities to discuss how to solve a task, give constructive arguments through repetition, verification and elaboration and thereby get involved in high order thinking in mathematics (Becker \& Selter, 1996) as logical reasoning and strategic learning.

Rojas-Drummond, Mercer and Dabrowski (2001) argue that different types of communication have different types of educational value for children (e.g. Samuelsson, 2008, 2010a, 2010b). Forms of knowing are embedded in, and mediated through language and the artefacts used in specific practices (Vygotsky, 1934/1986; Volosinov, 1929/1973, Wertsch, 1998). In this study, students use language in very different ways depending on their understanding of mathematics. Discursive contributions to group problems help children to advance, increasing their participation in mathematical speaking and thinking. Mercer (2004) found three distinctive ways of talking and thinking when people solve problems in a group.

A) Disputational talk - Children's talk is characterized by disagreement and individual decision making. There are few attempts to offer constructive criticism and notably short exchanges consisting of assertions and counter-assertions.

B) Cumulative talk - Children build positively but uncritically on what other children have said. It is characterized by repetitions, confirmations and elaboration.

C) Exploratory talk - Children engage critically but constructively with each other's ideas. Statements and suggestions are presented for shared consideration.

Mercer (2004) argues that the actual talking that goes on in any collaborative educational activity can be analysed on different levels, a) a linguistic level (What kind of speech acts do the children 
perform?, What topics are discussed?), b) a psychological level (How do the children interact?, What kinds of rules are they following?), and c) a cultural level (In what context is the talk accomplished?). In this study we focus on the psychological level, how the students interact.

\section{Aim}

The aim of this article was to investigate students' experience of a given mathematical problem. The following research questions will be addressed.

1. What types of interaction and communication occur when students experience the task as too difficult?

2. What types of interaction and communication occur when students experience the task as reasonable difficult?

3. What types of interaction and communication occur when students experience the task as too simple?

\section{Methodology}

The data this text draws upon originates from four group work sessions with Swedish students in secondary school (age 14). Three groups consist of four students (One group with girls, two groups with two girls and two boys) and one group consist of three students (Two girls and one boy). All four groups worked with problem solving tasks in mathematics. The group members were composed by their ability in terms of mathematics. Group number one consists of students with basic achievement in mathematics, group number two and three consists of students with medium achievement in mathematics and group number four consists of students with high achievement in mathematics. The group work sessions were documented with a video camera and then transcribed verbatim. Each of the recorded sessions lasted approximately around 20 minutes. In total the data amounts of 1 hour and 20 minutes.

\section{Analysis}

As has been said, the interaction between the pupils was videotaped and later transcribed. In the transcription, we chose not to note the pauses and other details in the transcript of the talks because they were not important for our study (cf. Mercer, 2004). However, we have listed events and practices that we observed when examining the video recorded conversations, which we thought were relevant for analysis and interpretation of the material. The observation excerpts are within parenthesis/interpolations in the results.

The transcribed data has been analyzed with a thematic analysis (Braun \& Clarke, 2006) and also used theoretical coding (Glaser, 1978) as follows. The analysis (a) began with an open coding very close to the empirical material. During the first coding, several codes emerged. These in turn, were elaborated and allocated into new parts in order to create wider sets of codes and become more abstract to form themes gradually. Three main themes were constructed, namely the task, group processes and communication. The analysis continued (b) focusing on the three themes, and new codes related to the themes were constructed from the empirical data. With the comparative method the themes were elaborated to develop each themes properties and dimensions to reach internal homogeneity and external heterogeneity (Patton, 1990). In the third phase of the analysis (c) the aim was to find out how the relations among the themes and their dimensions were related to each other, therefore theoretical coding was used (Glaser, 1978). Thereby, patterns and connections between the themes emerged which form the basis for the understanding of how the group processes and the communication between the students were influenced by how they experienced the difficulty with the task in presence.

\section{Ethical considerations}

The ethical guidelines of the Swedish Research Council have been followed. The students and their parents have given written permission for participation in the study and they have also been informed 
that they can cancel their participation whenever they want. All collected empirical data from the recordings have been handled, processed and reported in a way that an individual's identity and context are not going to reveal.

\section{Results}

Students can learn a great deal through joint effort and communication with peers. Working in small groups in the mathematical classroom is a teaching method where students can develop a fundamental component of mathematical knowledge when they are involved in mathematical processes. Group work involves a social and academic interaction between two or more students as they perform a task and customarily it is defined as 'students working together as a group or a team'. Students could just sit together in the group but work individually on separate parts of a group task and cooperation may occur but there is no necessity, they work in a group (i.e. cooperate). Students could also together be involved in and working on a common task with a mutual effort to utilise the group's competences, including problem-solving and reflection in order to produce a joint outcome, the work as a group (i.e. collaborate). Both individual work and work with mutual effort on the group task has been identified in this study.

The solving tasks, in the study, were of disjunctive character (Steiner, 1972) which means that there was no need to collaborate to solve the task since one of the members alone could came up with the answer. In this study the students work with two different tasks. The first problem they try to solve is a task where they investigate how many different ways an ant can walk from one corner of a cube to another corner. The ant is limited to walk on the edges of the cube. The second problem is a task where the students try to choose what figure, of five, which represent a turned-up presented cube.

However, the results demonstrate that how the joint work developed between the students depended on how they perceived the task's difficulty level. The results show what signifies the group's work and communication when students perceive the problem solving task as a) too difficult, b) reasonable difficult and c) too simple.

Consequently, the group works impact on mathematics learning depends on several factors. In this study the following aspects of the interaction processes will be discussed a) group interaction, b) quality of talk, c) mathematical processes with respect to how the students experience the mathematical task. The groups were composed in three different homogenous ability groups, namely students with (a) low ability, (b) normal ability, and (c) high ability for mathematics and the youth where the same age and worked with the same tasks. We have found that the group's beliefs with respect to the mathematical task, regardless of the students' ability, influence the groups' interaction and quality of talk. Consequently, the mathematical processes and thereby the educational value turned out to vary depending on the group's beliefs with respect to the mathematical task and not with respect to their ability.

\section{The task is experienced as too difficult}

When the task where experienced as too difficult the students tended to work individually side by side with little interactions around the task. If someone in the group attempted to interact with one or several group members with either words or acts the responses were few. The students work with "each track that rarely brings together". Commonly occurring is the following episode. "Nichole is looking at the task in front of her and beside she has a graph sheet drawing her pictures on. Johan and Therese are watching quietly. Sara, the fourth member of the team picks a few bricks on the desktop without devote much attention to the rest of the Group" (Group 4). Thus, the working processes in this section could characterize as cooperative work in a group, since they are sitting together, but the group do not use each individual competence to solve the problem and they interact, neither socially nor academically, with each other.

When the group members experienced the task as too difficult for the group to manage the quality of talk was characterized by disagreement and individual decision making. The excerpt below show how the students try to get involved in the problem solving process (turn 2-8), but the difficulty level of the mathematical problem requires the students to make individual thinking in order to understand the 
problem and what's actually asked for. Students give suggestions, suggestions that the peers give no attention to (turn 17-20).

01 Marcus - should we run with that... it's the same? ...no, it may not take the same way ... (points at the task) one there, two ...

02 Julia - if it goes there... I don't take what you mean

03 Marcus - you know... in each round (looks at Julia)

04 Nicklas - (points at the task) so... so...and so... (points with the forefinger around the 05 cube)

06 Marcus - otherwise, we can say ... (spinning around with the pen) so... three times,

then

07 four times (looks at Julia)

08 Julia - ah...now I make it

09 Marcus - and... hm will see ...one there

10 Julia - hm

11 Marcus - two, three, four

12 Julia - (points with the pen around the cube)... it will be five

13 Nicklas - (points on the cube) he starts there

14 Marcus - down there and there... skiit... what should we do?... one, two, three, four,

five

15 Nicklas - (draws on his paper)

16 Julia - (watches Marcus when he speaks and draw some lines)

17 Marcus - it can move here as well..

18 Julia - (points at the paper) it can move here...

19 Marcus - yes... six

20 Nicklas - (continues to draw on his paper... then look at the task silently)

21 Marcus - in any case, we have six, we do it this way... we sketch all of them...

(continues 22 to draw on his paper)

23 (15 seconds of silence)

24 Julia - (points on the cube) it could move this way ...

25 Nicklas - no... then it can go here to...

26 Julia - okey

27 Marcus (continues to draw lines on his paper)

28 (all three group members now work individually)

When the group experienced the task as too difficult the students did not exchange ideas and thereby do not develop their reasoning ability as much as they could have done if they were engaged in exploratory talk. The mathematical processes involved in the interaction were few. There are some occasions when the students count individually which could be related to procedural fluency, a skill in carrying out procedures flexibly (turn 11 and 14). In this case they're not perform any advanced mathematical procedures. The group members are only involved in simple arithmetic procedures.

Working with a task that is perceived as too difficult by the group members is not associated with cognitive development with respect to high order thinking in mathematics. When the task is too difficult, the students do not have the ability to formulate, represent, and solve the mathematical problems and thereby the interaction give no room to logical thoughts, reflections, explanations, and justifications.

\section{The task is experienced as reasonable difficult}

When the group members experienced the task as reasonable difficult the on-task interactions was moderate to intensive. This means that the students' discussed the task content and how to solve the problem in a way that "each track brings together" and the working processes could characterize as collaborative work as a group. The group interactions in the excerpt below is characterised by working on the common task with a common effort, using all group members' competences, in order to produce a joint outcome. In the interaction they listen to each other, they also asked questions and argued (see for example turn 2, 8, 13, 15, 17, 18, 24,32) if they did not understand or find something strange in the conversation. This means that they meet each other's perspective which will be both useful and instructive in the work with the common task. 
When the students experienced the task as reasonable difficult for the group the quality of the talk is characterize as critical discussions with constructive/crystallising arguments through repetition, verification and elaboration. The following excerpt show how all group members contribute with suggestions and arguments and collaboratively solve the task. The difficulty level of the mathematical problem is sufficiently challenging for the students. This makes them interested of the task which they also seem to have the ability to understand and through processing reach a joint solution.

01 Jessica - we take the next task. Which is the nearest way the ant should take? ... is this the

02 nearest way? (points at the task)

03 Natalia - (points at the task) ...so, so and so

04 Jessica - yes

05 Jessica - and there... it must be the nearest way!

06 Elin - but check... there is ... (points at the task)

07 Natalia - look here...it's going down

08 Maria - it doesn't have to go...

09 Natalia - no...look, it could move so, so and so (points at the task)

10 Maria - yes

11 Natalia - and as long as...

12 Maria - (points at the cube) one... two..

13 Jessica - yes but then there will be two ... there must be a nearest road

14 Natalia - this... the way we did it... when it going down so and so (points at the task) ...or 15 if it went this way so and so...is it the same?

16 Jessica - it says that it only can move...

17 Natalia - yes but then it can go so and so... (points at the task)

18 Maria - but it may cross...

19 Jessica - it may do it...

20 Teacher - it may go the nearest way but not necessary on the edges

21 Maria - yes but then it is like this... (shows with the forefinger on the cube)

22 Jessica - (take one cube and start to count ways)

23 Maria - (draws on the paper... Jessica, Natalia and Elin watches silently)

24 Jessica - it goes up there then?

25 Natalia - yes, it could go (points at the cube) ...oh it doesn't matter...

26 Maria - no (continues to draw)

27 Jessica - how long is it?

28 Natalia - what's the diameter?

29 Jessica -12

30 Maria - 12 at the border

31 Jessica - there..

32 Natalia - hey, the diameter is longer! (looks at Jessica)

33 Jessica - if you think that you have (draws on her paper) ...if all sides are 12, then

this also 34 is 12

35 Maria - no...

36 Natalia - no 12 and 12 and this one was $x$, how did you do then?

37 Maria - you take $12^{2}+12^{2}=x$ (writes)

38 Jessica -12 times 12 is 24

39 Maria - sch, use the calculator!

40 Elin - (uses the calculator) 288

41 Jessica - then we take the root out... (writes)

42 Elin - 16,97

43 (Jessica and Maria write)

44 Natalie - then it is

45 Maria - then this is 16.97 plus 12 (writes)

46 Elin - (uses the calculator) 16,97 plus 12 is 28,97

47 (Jessica and Maria write)

48 Maria - (looking at the task) what is 12 times 3? (continues to write)

49 Natalia - 34,56 
The advantage in the above presented group work lies in the scaffolding process whereby students' help each other advance. Providing and getting help and explanations may extend their mathematical knowledge, and verbalising can help students structure their thoughts. This exchange may encourage students to engage in higher-order thinking in mathematics. One important goals of mathematics courses, which could be related to high order thinking in mathematics, is to teach student logical reasoning. When the task is perceived as reasonable difficult the group members interact with each other in a way that gives them the opportunity to develop their capacity for adaptive reasoning which means logical thoughts, reflections, explanations, and justifications.

\section{The task is experienced as too simple}

When the group experienced the task as too simple the on-task interaction was minimal and, as working with a difficult task, the students worked with "each track that rarely brings together". Thus, the working processes could characterize as cooperative work, i.e. working in a group. The students sit together in a group but work individually on separate parts in the problem solving task and interaction may occur but there is no necessity, and if someone talks it will be to come up with a ready-made solution which has emerge/appear with a minimum of interaction between the group members. When the group members experienced the task as too simple for the group, the quality of talk was characterized by disagreement and individual decision making (turn 5, 7-12). The excerpt below show the lack of interactions and discussions in the problem solving, instead the students just ascertain their individual answer on the task.

01 Anna - (reads the task in silence)

$02 \mathrm{Jacob}$ - (points at the task)

03 Anna - wait, I must read (turn away Jacobs's hand)... which of these cubes could you get 04 by fold the right corner...

05 Olivia - what then ... fold the right corner...

06 (Jacob and Anna point, and makes movements with their fingers)

07 Fredrik - hm... I say a

08 Teacher - you also have to agree

09 Anna - I also think a ... if you fold everything to the right ...then this will be in the

10 middle...no

11 Jacob - if you fold around ... it will be so (looks at Fredrik)

12 Fredrik - then, it's a

If the task was experienced as too easy few opportunities to interact with peers was proven. Instead the group work was signified by individually decision making and individually problem solving the advantages of learning with a group was not fully used. The educational value in these processes is therefore limited to individual practicing of mathematical competencies as procedural knowledge.

\section{Summary}

Different ways of experience a mathematical task affect the interaction processes, quality talk and certain mathematical processes. The above presented interaction and modes of thinking are developed in qualitatively different collaborative relationships. In the table below we summarize the results.

Table 1. Different ways of experience a mathematical task affect interaction processes, quality talk and certain mathematical processes.

\begin{tabular}{llll}
\hline $\begin{array}{l}\text { Experienced } \\
\text { difficulties }\end{array}$ & Group interaction & Quality of talk & $\begin{array}{l}\text { Mathematical } \\
\text { processes }\end{array}$ \\
\hline too difficult & $\begin{array}{l}\text { Working in a group }- \\
\text { cooperative work }\end{array}$ & $\begin{array}{l}\text { Disagreement and } \\
\text { individual decision } \\
\text { making -disputational } \\
\text { talk }\end{array}$ & $\begin{array}{l}\text { Simple arithmetic } \\
\text { procedures }\end{array}$ \\
& & $\begin{array}{l}\text { Critical discussions with } \\
\text { constructive arguments } \\
\text { reasonable difficult }\end{array}$ & $\begin{array}{l}\text { Logical, thought, } \\
\text { reflections, } \\
\text { - exploratory talk }\end{array}$ \\
& $\begin{array}{l}\text { Working as a group } \\
\text { collaborative work }\end{array}$ & & \\
& & & \\
\hline
\end{tabular}




\begin{tabular}{llll}
\hline too simple. & $\begin{array}{l}\text { Working in a group }- \\
\text { cooperative work }\end{array}$ & $\begin{array}{l}\text { Disagreement and } \\
\text { individual decision } \\
\text { making - disputational } \\
\text { talk }\end{array}$ & $\begin{array}{l}\text { Simple arithmetic } \\
\text { procedures }\end{array}$ \\
& & \\
\hline
\end{tabular}

\section{Discussion}

Working in small groups is a commonly used teaching method where children can develop a fundamental component of mathematical knowledge as for instance adaptive reasoning (Ross, 1998; Kilpatrick et. al. 2001). Thus, the peer collaborations impact on mathematics learning depends on several factors such as age (Hogan \& Tudge, 1999) and task (Phelps \& Damon, 1989). In this study the students where the same age and worked with the same tasks, despite that, the interaction, the quality of talk and thereby the educational value turned out to vary in the groups. We found that the group's experience of the task had an impact on the pattern of interaction when they tried to solve the mathematical tasks. The same patterns were found independently of students' mathematics ability. Groups with high ability students showed the same interaction pattern as average and low ability student when they experienced the task as too difficult, reasonable difficult and too simple. Earlier research has shown that students confidence have an impact on the interaction processes when solving mathematical problems (Gillies \& Boyle, 2010; Rojas-Drummond \& Mercer, 2003; White \& Dinos, 2010).

\section{The interaction}

Students could just sit together in the group but work individually on separate parts of a group task, they work in a group (i.e. cooperate). Students could also together be involved in and working on a common task with a common effort to utilise the group's competences, they work as a group (i.e. collaborate). Both cooperation and collaboration has been identified in this study. When students experienced the task reasonable difficult they start to work collaboratively as a group and thereby the group work was function as a means and the students have opportunity to obtain both academic and social knowledge (i.e. collaboration abilities). When students experienced the task as demanding or easy they start to work more cooperatively in a group and the group work functions as an object (Baines et al., 2007; Gillies, 2003; Johnson \& Johnson 2004; Summers et al. 2005). In these situations the students have opportunity to social but not academic knowledge.

\section{The quality of talk and educational value}

If the student experienced the task as too difficult or too simple they used disputational talk, and when they experienced the task as reasonable difficult the groups used cumulative or exploratory talk (cf. Mercer, 1994). Earlier research suggests that the key element of effective peer collaboration is the active exchange of ideas through verbal communication (Rogoff, 1990; Samaha \& De Lisi, 2000; Ryve, Nilsson \& Pettersson, 2013, Webb \& Favier, 1999). In this study these types of exchanges occurred when the children were engaged in a task as they experienced as reasonable difficult. They challenged each other, requested for clarification and they practiced their reasoning ability.

When the student experienced the task as to demanding or to easy quality of talk could be related to disputational talk. The student did not exchange ideas and thereby did not develop their reasoning ability as much as they do when they are engaged in exploratory talk. In this study the disputational talk were used to inform the other student of how they have counted, agreement or disagreement. The students only were practicing simple arithmetic procedures, individual decisions and individual counting when they worked with tasks they experienced as too difficult or to simple. (cf. Säljö, 2000; Mercer, 2004). 


\section{Didactical Implications}

The results show how students' experience of the mathematical task affect the groups' interaction and thereby what is possible to learn in mathematics. Earlier research has shown that programmes that endeavoured peer collaboration as a teaching method reported good results (Goods \& Gailbraith, 1996; Leiken \& Zaslavsky, 1997). From a teacher's perspective, when mathematics work is complex (Kilpatrick et. al., 2001), it is essential to know how the selection of task affect the interaction in a group work and that different quality of talk have different impact on what learning outcomes that is possible. Talks where students are able to exchange ideas seem to give the student the opportunity to practice their adaptive reasoning.

This study gives evidence that students experience of a task in mathematics affect the collaborative work with mathematical problems exposing different cognitive processes (cf. Säljö, 2000; Mercer, 2004). This was also shown by Rojas-Drummond et al. (2001) who argued that different types of interaction have different types of educational value for children.

The results also show that teachers' settings of the problem and how the students manage the interaction processes in the group are important to what competencies students are exposed to and what they thereby are able to learn. From a learning perspective when using group work it is of advantage to let the mode function as a mean and let it be a base for obtaining both academic knowledge and collaboration abilities (Baines et al., 2007; Gillies, 2003; Johnson \& Johnson 2004; Summers et al. 2005).

\section{The Strength and Limitations of the Study}

Strength with this type of qualitative research is that our issues have been analysed in detail and in depth. Thus an obvious limitation of this study is the quantity of data. Data are collected from few cases so findings cannot be generalized to a larger population. This means that there is a difficulty of extending current findings to different task, participants and fields of study.

\section{References}

Baines, E., Blatchford, P. \& Chowne, A. (2007). Improving the effectiveness of collaborative group work in primary schools: Effects on science attainment. British Educational Research Journal, 33, 663-680.

Braun, V., \& Clarke, V. (2006). Using thematic analysis in psychology. Qualitative Research in Psychology, 3, 77-101.

Becker, J. P., \& Selter, C. (1996). Elementary school practices. In M. A. Clements, A. J. Bishop, C. Keitel, J. Kilpatrick \& F. K. S. Leung (Eds.), International Handbook of Mathematics Education (pp. 511-564). Dordrecht: Kluwer.

Cohen, E. G. (1994a). Designing groupwork. New York: Teachers College Press.

Cohen, E. G. (1994b). Restructuring the classroom: Conditions for productive small groups. Review of Educational Research, 64, 1-35.

Doise, W., \& Mugny, G. (1984). The social development of the intellect. Oxford: Pergamon Press.

Hammar Chiriac, E. (2011a). Research on group work in education. New York: Nova Science Publishers, Inc.

Hammar Chiriac, E. (2011b). Research on group work in education. In F. Columbus (Ed.), Emerging Issues in Compulsory Education (pp. 25-44). New York: Nova Science Publishers, Inc.

Hammar Chiriac, E., \& Forslund Frykedal, K. (2011). Management of group work as a classroom activity. World Journal of Education, 1, 3-16.

Gabriele, A. J., \& Montecinos, C. (2001). Collaborating with a skilled peer: The influence of achievement goals and perceptions of partners' competence on the participation and learning of low-achieving students. Journal of Experimental Education, 69, 152-167. 
Garton, A. F., \& Pratt, C. (2001). Peer assistance in children's problem solving. British Journal of Developmental Psychology, 19, 307-318.

Gillies, R.M. (2003). Structuring cooperative group work in classrooms. International Journal of Educational Research 39, 35-49.

Gillies, R. M., \& Boyle, M. (2010). Teachers' reflection on cooperative learning: Issues of implementing. Teaching and Teacher Education, 26, 933-940.

Glaser, B. G. (1978). Theoretical sensitivity. Mill Valley, CA: Sociology Press.

Goods, M., \& Gailbraith, P. (1996). Do it this way! Metacognitive strategies in collaborative mathematical problem-solving. Educational Studies in Mathematics, 30, 229-260.

Hertz-Lazarowitz, R. (1989). Cooperation and helping in the classroom: A contextual approach. International Journal of Educational Research, 13, 113-119.

Hofer, B. K., \& Pintrich, P. R. (1997). The development of epistemological theories: beliefs about knowledge and knowing and their relation to learning. Review of Educational Research, 67, 88140.

Hogan, D., \& Tudge, J. (1999). Implications of Vygotsky's theory for peer learning. In A. O'Donnell \& A. King (Eds.), Cognitive perspectives on peer learning (pp. 39-65). New Jersey: Erlbaum Press.

Johnson, D., \& Johnson, F. (2004). Joining together: Group theory and group skills. Boston: Allyn and Bacon.

Järvenoja, H., \& Järvelä, S. (2009). Emotion control in collaborative learning situations: Do students regulate emotions evoked by social challenges? British Journal of Educational Psychology, 79, 463-481.

Kilpatrick, J., Swafford, J., \& Findell, B. (2001). Adding it up: Helping children learn mathematics. Mathematics Learning Study Committee. Washington D.C.: National Academy Press.

Leikin, R., \& Zaslavsky, O. (1997). Facilitating student interaction in mathematics in a cooperative learning setting. Journal for Research in Mathematics Education, 28 (3), 331-254.

Mercer, N. (2004). Sociocultural discourse analysis: analysing classroom talk as a social mode of thinking. Journal of Applied Linguistics, 1, 137-168.

National Agency of Education. (2011). Läroplan för grundskolan, Lgr11. Stockholm: Department of Education.

Oliveira, A. W., \& Sadler, T. (2008) Interactive patterns and conceptual convergence during student collaboration in science. Journal of Research in Science Teaching, 45, 634-658.

Patton, M. Q. (1990). Qualitative evaluation and research methods. London: Sage Publications.

Phelps, E., \& Damon, W. (1989). Problem solving with equals: Peer collaboration as a context for learning mathematics and spatial concepts. Journal of Educational Psychology, 81, 639-646.

Rogoff, B. (1990). Apprenticeship in thinking: Cognitive development in social context. New York: Oxford University Press.

Rojas-Drummond, S., \& Mercer, N. (2003). Scaffolding the development of effective collaboration and learning. International Journal of Educational Research 39, 99-111.

Rojas-Drummond, S., Mercer, N., \& Dabrowski, E. (2001). Collaboration, scaffolding and the promotion of problem solving strategies in Mexican pre-schoolers. European Journal of Psychology of Education, 16, 179-196.

Ross, K. A. (1998). Doing and proving: the place of algorithms and proof in school mathematics. American Mathematical Monthly, 5, 252-255.

Ryve, A., Nilsson, P., \& Pettersson, K. (2013). Analyzing effective communication in mathematics group work: The role of visual mediators and technical terms. Educational Studies in Mathematics, $82,497-514$. 
Samaha, N. V., \& DeLisi, R. (2000). Peer collaboration on a nonverbal reasoning task by urban minority students. Journal of Experimental Education, 69, 5-14.

Samuelsson, J. (2008). The impact of different teaching methods on students' arithmetic and selfregulated learning skills. Educational psychology in practice ,3, 237-250.

Samuelsson, J. (2010a). The Impact of Teaching Approaches on Students' Mathematical Proficiency in Compulsory School in Sweden. International Electronic Journal in Mathematics Education, 5, 13061330.

Samuelsson, J. (2010b). The effect of peer collaboration on children's arithmetic and self-regulated learning skills. Electronic Journal of Science and Mathematics Education, 2, 130-153.

Steiner, I.D. (1972). Group process and productivity. New York: Academic Press.

Strough, J., Berg, C. A. \& Meegan, S. P. (2001). Friendship and gender differences in task and social interpretations of peer collaborative problem solving. Social Development, 10, 1-22.

Summers, J. J., Beretvas, S. N., Svinciki, M. D., \& Gorin, J. S. (2005). Evaluating collaborative learning and community. Journal of Experimental Education, 73, 165-188.

Tudge, J. R. H., \& Winterhoff, P. (1993). Vygotsky, Piaget and Bandura: Perspectives on the relations between the social world and cognitive development. Human Development, 36, 61-81.

Tudge, J. R. H., Winterhoff, P., \& Hogan (1996). The cognitive consequences of collaborative problem solving with and without feedback. Child Development, 67, 2892-2909.

Webb, N. M., \& Favier, S. (1999). Developing productive group interaction in middle school mathematics. In A. M. O'Donnell \& A. King (Eds.), Cognitive perspectives on peer learning (pp. 117-149). New Jersey: Erlbaum.

Webb, N. M., \& Mastergeorge, A. (2003). Promoting effective helping behaviour in peer-directed groups. International Journal of Educational Research, 39, 73-97.

Wertsch, J. (1998). Mind as action. Cambridge, MA: Harvard University Press.

White, R., \& Dinos, S. (2010). Investigating the impact of mediated learning experiences on cooperative peer communication during group initiatives. Journal of Experiential Education, 32, 226-238.

Volosinov, V. N. (1973). Marxism and the philosohy of language. [Translated by L. Matejka and I. R.Titunik]. New York: Seminar Press.

Vygotsky, L. S. (1934/1986). Thought and language. [translated by A. Kozulin]. Cambridge, Mass.: MIT Press. 